\title{
Gordon Lish
}

\section{No Swifter Nor More Terrible a Confession}

The sentence I most dread hearing is please, sir, step to the side into the street, sir. Or I suspect I should have written it "Please, sir, step to the side into the street, sir."

Or said at least quote, unquote.

I don't know why this is.

I don't think it owes to my practice of walking always as far from the curb as I can get. Which means near to the store fronts, near to the shop fronts, and therefore not infrequently straight into the path of those citizens ambling closely there-along in order that they have an unobstructed line of sight into the windows of American commerce.

But as to the practice I mentioned, I certainly do indeed know what this owes to, yes-i.e., which I have taken care to italicize in witness of my dereliction firstmost among the aforesaids-i.e., keeping my motion, when it is parallel to the thoroughfare, as distant on the perpendicular as I can get it from the curb, this on account of the cant of the sidewalk.

They cant them here where I live.

For to provide for the run-off into the street.

Of rain, of snow melt, of what-have-you.

Creating thereby an inclined plane-however slight the elevation of which I see no reason for me not to seize advantage of. For I am short, am of unaverage measure, am of below-average stature-and therefore feel myself ever so much less challenged when passing my humanfellowkind if improved, bolstered, increased by the not at all dismissable gain the higher ground guarantees me.

At least when I am here in the city.

But when do I ever take myself thither from this city? I think never. Yet were I to, it first comes clear to me first this very instant, were I the undersigned to venture forth from here into bourne and field, into field and bourne, then mightn't I be free, even for the littlest while, of this dreading that so tasks me?

Such an awful sentence. 
Please, sir, step to the side into the street, sir.

Unless it were to have the power to pursue me into all its cruel transmutings-so that it could become, in its most pastoral use, sir, step to the side into the hollow, sir-or, in its most fanciful, the pit, the chasm, the abyss.

Quotes and unquotes all around, everyone.

Yours truly, the author of this. 